Lyons, W. R. (1958). Proc. R. Soc. B r49, 303.

Mishkinsky, J., Dikstein, S., Ben-David, M., Azeroual, J. \& Sulman, F. G. (r967). Proc. Soc. exp. Biol. Med. 125, 360 .

Pope, G. S., Jones, H. E. H. \& Waynforth, H. B. (1965). F. Endocrin. 33, 385.

Reynolds, M. (1965). Fedn Proc. Fedn Am. Socs exp. Biol. 24, 45 I.

Rowland, S. J., Roy, J. H. B., Sears, H. J. \& Thompson, S. Y. (I953). F. Dairy Res. zo, I6.

Schalch, D. S. \& Reichlin, S. (r966). Endocrinology 79, 275.

Selye, I. (r934). Am. F. Physiol. 107, 535 .

Short, R. V. (1958). F. Endocrin. 16, 426.

Smith, A., Wheelock, J. V. Dodd, F. H. (1966). \%. Dairy Sci. 49, 895.

Talwalker, P. K. \& Meites, J. (Ig6r). Proc. Soc. exp. Biol. Med. ro7, 880.

Tverskoi, G. B. (1957). Zh. obschch. Biol. 18, 169.

Wheelock, J. V., Smith, A. \& Dodd, F. H. (1967). F. Dairy Res. 34, I5 I.

\title{
The amount and physical form of feed and milk secretion in the cow
}

\section{By D. G. Armstrong, University of Newcastle upon Tyne}

Among factors which affect milk secretion in the cow are breed, age, stage of lactation, disease, management and nutrition. This paper is concerned with two aspects of the last-mentioned. In the previous contributions to this Symposium the precursors of milk constituents in the blood and the control mechanisms and metabolic pathways by which they are synthesized into milk constituents have been discussed. In this paper the extent to which present knowledge concerning the end-products of digestion and their subsequent metabolism within the body can account for the known effects of the amount of food and its physical form on milk yield and composition will be examined.

Early intervention of microbial fermentation in the digestive processes of the ruminant complicates the task on at least two counts. Firstly reliable quantitative information on the end-products of digestion in the lactating cow is almost totally lacking. Secondly the end-products of carbohydrate digestion, the volatile fatty acids (VFA), are metabolized within the body by quite different metabolic pathways and, while a considerable amount is known concerning the specific pathways followed by individual acids, much less is known concerning the metabolic interrelationships of the acids within the body. A third complication, not necessarily restricted to the ruminant, is the capacity of the lactating animal to draw upon supplies of body energy to maintain milk secretion during early lactation.

Among the more recent of several excellent reviews on the subject of nutrition and milk secretion are those by Rook ( $196 \mathrm{r} a, b$ ), Van Soest ( 1963 ), Huber $\&$ Boman (1966b) and Kirchgessner, Friesecke \& Koch (1 967 ). Only brief reference will therefore be made to the effects on milk yield and composition, of the amount of food fed and its physical form. It is necessary to note that some nutritional factors induce equal changes in yicld of milk and its principal components, namely fat and solidsnot-fat (SNF) comprising essentially lactose and protein; such factors therefore affect milk yield but not milk composition. Some factors induce changes in certain 
constitutents without change in milk yield and thus only affect milk composition; others can induce changes in yield and composition.

Plane of energy nutrition and milk secretion. As the plane of energy nutrition rises the yield of milk increases although at an ever diminishing rate; the decline in rate of increase is associated with increasing live-weight gain (see Huber \& Boman I $966 a$ ). Concerning milk composition there is little effect on lactose content (Holmes, Arnold \& Provan, r 960; Castle, Drysdale \& Waite, r96r ; Rook \& Line, г 961), unless the energy level is considerably restricted when a small decline may occur (Rook, Line \& Rowland, I960; Rook \& Line, I96r). The protein content of milk increases as energy level is raised, the changes being more marked at low levels of energy than at high (see Kirchgessner et al. 1967). Thus SNF content rises with level of energy fed and the changes are almost entirely accounted for by changes in content of casein, $\alpha$-lactalbumin and $\beta$-lactoglobulin (Rook \& Iine, 1961). The increase in the mineral-lactose fraction as energy intake increased, reported by Huber $\&$ Boman ( $1966 a$ ), may in part be due to increase in mineral content with rise in energy intake (see Holmes et al. 1960; Castle et al. 1961; Rook \& Line, I961).

Providing that the change in energy level is not effected by alterations in ration composition which induce marked changes in the relative proportions of the VFA in the rumen, changes in energy level have little effect on fat content (see Kirchgessner et al. 1967). Prolonged underfeeding may induce low milk fat contents.

Level of dietary protein and milk secretion. For a given level of energy intake increases in level of protein fed above recognized standards have little effect on milk yield or composition (see Kirchgessner et al. 1967) although there are significant increases in non-protein nitrogen (NPN) content which because of the small amounts present do not affect SNF content significantly (Rook \& Line, 1962). Levels of dietary protein considerably below requirement lead to a decline in milk yield and protein content.

Level of dietary fat and milk secretion. The responses in milk secretion to additions of dietary fat reported in the literature suggest appreciable differences between saturated and unsaturated fats. Undoubtedly the response to dietary fats is considerably influenced by events taking place within the rumen. This subject will be dealt with by Moore \& Steele (1968).

Physical nature of the diet and milk secretion. Considerable reductions in the amount of physically fibrous constituents in the diet induce marked falls in milk fat content with little effect on milk yield or SNF content. Such diets may comprise lowroughage-high-concentrate rations (Huber \& Boman, $1966 a$ ) or may result from the grinding of the roughage (Balch, Broster, Rook \& Tuck, I965) with or without pelleting. Low-fat milk can also result from the treatment of cereals before feeding, for example the cooking (flaking) of maize (Balch et al. 1965).

End-products of digestion. The relationship between increment in feed dry matter and amount of additional energy absorbed is not necessarily a linear one. The digestibility of the supplement is an important factor. Another is the decline in digestibility that occurs at the high levels of food intake achieved by high-yielding dairy cows. Thus Moe, Reid \& Tyrrell (1965) observed depressions in total digestible 
nutrient values per increment of food intake equivalent to that for maintenance, ranging from $2 \cdot$ I to $6 \cdot 2 \%$ in experiments with dairy cows fed a variety of rations up to six times maintenance requirements. It must be noted however that, in experiments with lactating cows fed at levels of intake up to three times maintenance requirements, Flatt ( 1966$)$ found that the decrease in apparent digestibility as intake increased was compensated for by reduced energy losses as methane and in urine; the concentration of metabolizable energy per unit gross energy in feed remained almost constant.

The major end-products of carbohydrate digestion are the VFA and with some cereals lactic acid, and the relative proportions of acids present on a mean daily basis tend to be a characteristic of the ration fed. Results for a considerable variety of feeds have been presented by Bath \& Rook (1963, r965) and by Rook (1964) and the general picture which emerges from these findings is that as the proportion of structural carbohydrate in the total feed decreases the proportion of acetic acid expressed as a molar percentage of total VFA also declines. Where the depression in structural carbohydrate content in the total feed is due to the feeding of an increased proportion of cereal or cereal-based concentrate then the decline in the molar proportion of acetate may be associated with an increased concentration of propionate or of butyrate or of both. Thus with flaked maize the decline in acetate is associated with a marked rise in propionate (Storry \& Rook, I966), whereas with barley Donefer, Lloyd \& Crampton (1962) found a compensatory increase in butyrate but little change in propionate.

Increases in intake of roughages fed singly have little effect on the molar proportions of the acids present (Williams \& Christian, 1956-7; Bath \& Rook, 1963), but with hay-concentrate mixtures where the proportions are kept constant as intake rises there is evidence (Bath \& Rook, 1963 ) that the acetic to propionic acid ratio narrows. When the plane of energy nutrition is increased by feeding an increased proportion of concentrates the general effect is to narrow the ratio of acetic to propionic acid. The same effect is induced by grinding the roughage or by heat treatment of cercals before feeding (Balch et al. 1965 ).

Another important consideration is the effect that an increase in energy intake may have on the passage of $\alpha$-linked glucose polymer from the reticulo-rumen. Such material when subjected to the carbohydrase enzymes of the small intestine may make an appreciable contribution to the glucose economy of the animal. In sheep fed high-grain rations the $\alpha$-linked polymer which enters the small intestine amounts to some $8 \%$ of that in the feed (Armstrong, Seeley \& MacRae, 1967). The studies of Karr, Little \& Mitchell (I966) suggest that with steers fed high-grain rations considerably higher quantities of $\alpha$-linked polymer enter the small intestine and that the amounts increase with increasing dietary starch intake.

Little is yet known concerning the quantitative significance of microbial fermentation on the supply of essential amino acids to the lactating cow. Certainly the studies of Bigwood (1964) and of Clarke, Ellinger \& Phillipson (1966) point to the very marked changes both in amount and amino acid make-up of the protein as between that entering and that leaving the rumen.

Amounts of volatile fatty acids absorbed. The studies of Leng \& Leonard (1965) 
and Leng \& Brett (1966) indicate that production rates of individual VFA are linearly related to their concentrations in rumen liquor and that lower, effective rates of production for each acid can be calculated by allowing for the known interconversion of VFA within the rumen-particularly significant in the case of acetic and butyric acids. As Leng has pointed out, such effective rates of production will probably be close to the quantities of individual VFA absorbed unless appreciable quantities undergo further metabolism within the rumen. With the last qualification in mindand there is little relevant information available - and if the assumption is made that the rates of interconversion between acids are fairly constant irrespective of diet, then it seems reasonable to infer that the relative concentrations of individual VFA within the rumen closely reflect the relative amounts absorbed.

Volatile fatty acids and blood composition. In the present context the important consideration is the relation between the acids absorbed and concentrations of milkconstituent precursors in the blood flowing to the mammary gland. With acetate much of it passes to the liver and can enter the extrahepatic circulation although a small part is metabolized to $\mathrm{D}(-)-\beta$-hydroxybutyrate $(\mathrm{BOH})$ in the rumen epithelium. Butyrate is completely metabolized to $\mathrm{BOH}$ in the rumen epithelium or liver and this metabolite can also enter the extrahepatic circulation. With propionate some is metabolized in the rumen epithelium to lactic acid and the remainder is removed, almost quantitatively, by the liver (for references see Armstrong, i 965 ). Recent studies by Bergman, Roe \& Kon (r966) with sheep suggest that some $50 \%$ of propionate is converted into glucose. Thus of the three major acids absorbed only acetate appears in any amount in arterial blood; butyrate can contribute $\mathrm{BOH}$, while propionic (and lactic) acid can increase the concentrations of glucose.

There is evidence in fed sheep (Annison, Leng, Lindsay \& White, 1963) and in lactating dairy cows (Storry \& Rook, $1_{96} 5^{a}$ ) that as the supply of propionate to the liver is increased acetate levels in venous blood are reduced, although whether the fall is due to inhibition of endogenous acetate production or to increased removal of acetate from the blood is not known. There is also evidence that, as the concentration of glucose is increased, fat mobilization from adipose tissue is reduced (Annison, I960; McClymont \& Vallance, 1962). Possible mechanisms by which such effects may be brought about will be discussed later.

Recent experiments with lactating cows. The effect of changes in the relative proportions of VFA in the rumen on venous blood composition have been reported by Storry \& Rook ( $1965 a$ ). The experiments, involving intraruminal infusions of VFA in lactating dairy cows have also yielded information on the significance of changes in the relative proportions of VFA in the rumen with respect to yield and composition of milk (Rook \& Balch, I96I; Rook, Balch \& Johnson, 1965) or with respect to yield of milk fat and its composition (Storry \& Rook, 1965a, I966). Some of the changes in blood composition and milk secretion noted in these studies are shown in Table 1 .

The intraruminal infusion of acetic acid induced a significant rise in blood levels of acetone and acetoacetic acid (AAA), BOH and especially in total VFA in which the effect was due to acetate alone. In one animal there was a significant decline in 
Vol. 27

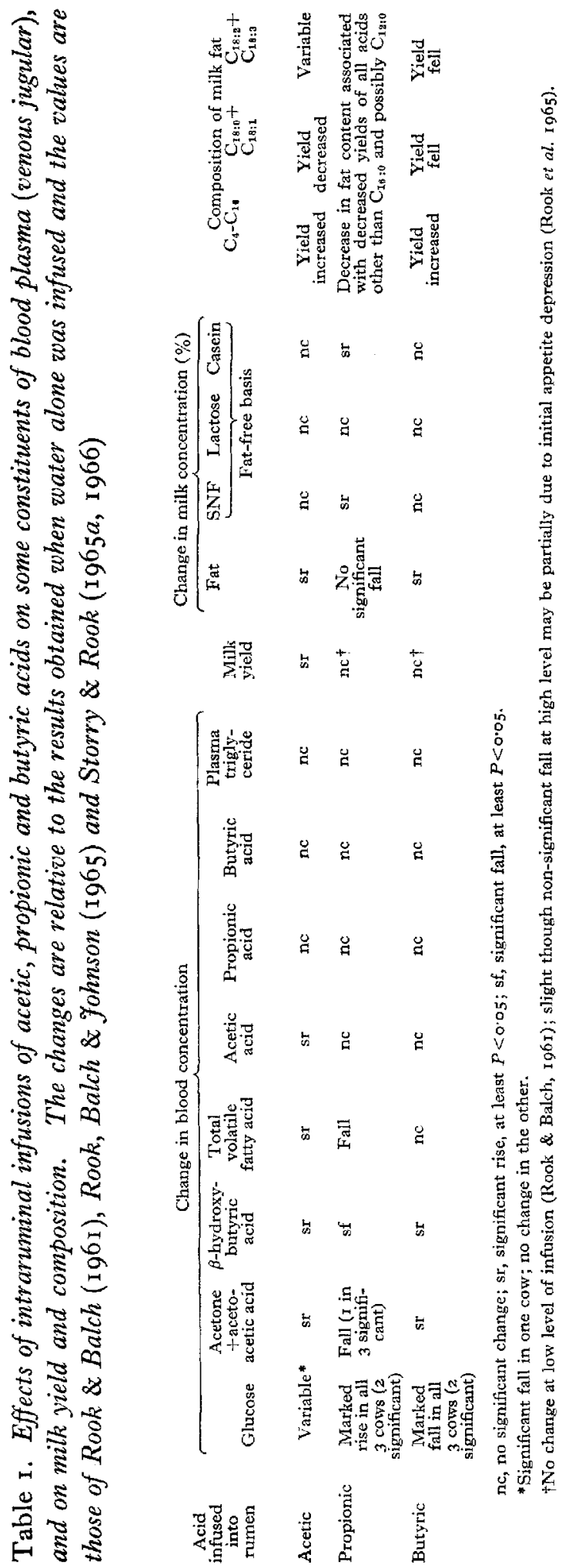


glucose, in the other no change. Propionic acid markedly increased glucose levels in all three cows (significantly in two cows) with no change in VFA and lower levels of AAA and BOH. Butyric acid resulted in marked increases in AAA and $\mathrm{BOH}$, no change in total VFA and marked falls in plasma glucose. None of the infusions affected plasma triglyceride levels, but the authors point out that in the cows examined the levels were low and variable.

It can also be seen from Table $\mathrm{r}$ that infusion of acetic acid into the rumen increased milk yield and fat content with no affect on SNF, lactose or casein contents. The intraruminal infusion of butyric acid did not significantly affect milk yield, but induced a marked rise in fat content which, like that resulting from the infusion of acetic acid, was associated with increased yields of $\mathrm{C}_{4}-\mathrm{C}_{16}$ acids and decreased yields of $\mathrm{C}_{18 ; 0}$ and $\mathrm{C}_{18: 1}$ acids. Propionic acid did not affect milk yield but resulted in a marked depression in fat content which was associated with decreased yields of all fatty acids other than palmitic and possibly lauric. The three-carbon acid also induced significant changes in SNF and casein contents.

Storry \& Rook $(1965 b$, 1966) have examined the effects of diets low in hay and high in flaked maize on the secretion and composition of milk fat; in the first-mentioned study changes in blood composition were reported, in the second, changes in rumen VFA proportions. Different cows were used in these two studies and there were slight differences in the rations fed. In both studies the change from a normal hay-concentrate ration to one low in hay and high in flaked maize resulted in a marked fall in milk fat content. The change from a diet high in hay to one low in hay was reflected in the rumen by a marked fall in the proportion of acetate, increase in that of propionate and little change in that of butyric acid. Lactic acid increased appreciably. Abrupt re-introduction of the normal hay-concentrate ration resulted in return of the proportions of acids in rumen liquor to their original levels within 4 days although milk fat recovery took some $2-3$ weeks (Storry \& Rook, I966). The changes in blood composition (venous jugular) associated with the change to a low-hay diet (Rook \& Storry, $1965^{b}$ ) were a marked drop in acetate and BOH levels, decline in triglyceride and rise in glucose and lactate levels. On re-introduction of the normal hay-concentrate ration, blood acetate, $\mathrm{BOH}$ and triglyceride increased and these changes were associated with declines in glucose and lactate.

Recent studies by Opstvedt \& Ronning (1967) show clearly the differences in fatty acid composition of milk fat yielded by cows fed all-roughage compared with allconcentrate rations. In studies with Holstein cows in carly to mid-lactation and given equal intakes of dry matter as chopped lucerne or as a concentrate containing $80 \%$ steam-rolled barley, the cows fed concentrates showed a marked reduction in yield of fat and fat content. The amounts of all major fatty acids were reduced, but the magnitude of the decreases were considerably less for the lower saturated acids $\left(\mathrm{C}_{4}-\mathrm{C}_{14}\right)$ and for the higher unsaturated acids $\left(\mathrm{C}_{18: 1,2,: 3}\right)$ than for the higher saturated fatty acids $\left(\mathrm{C}_{16} ; \mathrm{C}_{18}\right)$. Some $74 \%$ of the total fatty acid reduction observed, corrected for slight increases in certain unsaturated acids, was accountable to reduction of fatty acids $\mathrm{C}_{16}$ or higher.

The above-mentioned studies suggest that a major part of the depression in milk 
fat that occurs on high-concentrate rations is associated with a decline in the incorporation of plasma triglycerides into milk fat. One mechanism by which such an effect might be induced is through the marked rise in $\mathrm{L}-\alpha-$ glycerolphosphate dehydrogenase activity shown to occur in the adipose tissue of lactating cows fed an all-concentrate in contrast to an all-hay diet (Opstvedt, Baldwin \& Ronning, 1967). These workers postulate that the increase in activity of this enzyme would ensure the rapid re-esterification of fatty acids in adipose tissue resulting in a decreased release of free fatty acids (FFA) from adipose tissue into blood. Since plasma FFA are converted into plasma triglyceride in the liver (re-entering the blood as low-density lipoprotein), the plasma triglyceride level in arterial blood would decline. These workers also showed that the specific activities of a number of other enzymes concerned with fat synthesis were markedly higher in the adipose tissue of the cows fed concentrates than in that from cows fed hay alone, while the specific activitics in mammary gland tissue tended to be lower. Thus in concentrate-fed animals the enzyme capacity for fatty acid and fat synthesis by adipose tissue might be increased and that in the mammary gland lowered. Both mechanisms would operate to reduce the concentrations of the milk fat precursors (triglyceride and acetate) in blood. The findings of Opstvedt et al. ( 1967 ) may also explain the observation of Storry \& Rook (1966) that in cows established on low-hay diets intraruminal infusion of acetic acid only resulted in an increase in milk fat content amounting to some $25 \%$ of the loss associated with the transfer to the low-hay diet.

Interpretation of the observed nutritional effects on milk secretion. Fig. I summarizes some of the more important relationships between end-products of digestion, precursors of milk constituents in the blood and milk secretion. From the available evidence it appears that the depression in milk fat content observed when large amounts of heat-treated cereals, with or without ground roughage, are fed is associated with low ratios of acetate to propionate absorbed from the rumen and a resulting suppression in the mobilization of adipose tissue to maintain plasma triglyceride levels, as suggested by McClymont \& Vallance (1962). Part of the depression may also arise from a decrease in synthesis from acetate of lower saturated fatty acids in the mammary gland. Whether the lower levels of acetate reaching the gland reflect an absolute shortage of exogenous acetate, reflect an increased synthesis of acetate into fat in adipose tissue or result from reduction in endogenous acetate production, it is not possible to say. Two mechanisms that might contribute to a reduction in endogenous acetate production are decrease in release of FFA from adipose tissue and reduced gluconeogenesis from protein as a result of the increased supplies of glucose precursor (propionate) reaching the liver.

The increase in milk yield that occurs with increase in plane of nutrition is probably associated with increases in the amounts of precursors for milk synthesis reaching the mammary gland. Thus Rook \& Line (196I) reported significant increases in VFA in arterial blood and of $\alpha$-amino nitrogen in venous blood with increase in energy intake. It must be noted, however, that in these studies the increase in plane of nutrition was effected by changing the proportion of hay to concentrates fed, and the kind of concentrate. No information is available on the changes in concentration of pre- 
Milk constituent

I. Lactose

2. Proteins

3. Fat

(a) glycerol

(b) fatty acids

$\begin{array}{ll}\text { i. } \mathrm{C}_{4}-\mathrm{C}_{14} & \begin{array}{l}\text { 1. Acetate* } \\ \text { 2. } \mathrm{D}(--)-\beta \text {-hydroxy- } \\ \text { butyrate }\end{array} \\ \text { ii. } \mathrm{C}_{10} & \begin{array}{l}\text { 1. Acetate } \\ \text { 2. Triglyceridet }\end{array} \\ \text { iii. } \mathrm{C}_{18} \text { acids } & \text { Triglycerides }\end{array}$

in blood

Glucose

Amino acids

Glucose
Principal precursors

Acetate
Butyrate (small amount from
acetate)
$\leftarrow$ as for $\mathrm{C}_{4}-\mathrm{C}_{\mathbf{1 4}}$ acids
Long-chain fatty acids leaving
rumen
Long-chain fatty acids leaving
rumen

\author{
i. Propionic and lactic acids \\ Amino acids
}

Site of absorption

Rumen

Small intestine

Small intestine

Small intestine

Small intestine

* Some acetate arises from endogenous production within the body.

†Triglycerides also arise as remobilised depot triglycerides. Thus energy-yielding substrates surplus to requirement in late lactation or in dry period may act as precursors.

4. Oxidative metabolism I. Glucose

2. Acetate

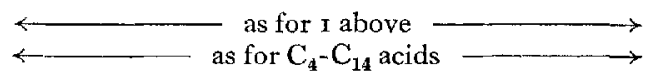

If milk yield is related to lactose synthesis and oxidative metabolism then:
5. Milk yield
I. Glucose
2. Acetate
$\stackrel{\leftarrow}{\longleftarrow}$ as for $\mathrm{I}$ above $\mathrm{C}_{4}-\mathrm{C}_{14}$ acids

Fig. I. Qualitative relationships between milk secretion, blood precursors and end-products of digestion in cows.

cursors in arterial blood induced through feeding increased amounts of the same ration. Among factors which might contribute to the observed rise in protein content of milk with increase in plane of nutrition could be increased efficiency of nitrogen capture in the rumen resulting in an increase in the relative amounts of amino acid nitrogen absorbed from the small intestine, reduced gluconeogenesis from amino acid within the body and an increased capacity for protein synthesis with the gland as availability of substrates for oxidative metabolism increases.

An interesting finding of Rook and his colleagues is the increase in milk yield resulting from acetate infusion into the rumen (see Table $\mathrm{I}$ ). If the effect is mediated through increased levels of acetate reaching the gland then one possible explanation is that acetate is exerting its effect through the contribution it can make to oxidative metabolism, thus sparing glucose. This would imply that glucose uptake by the gland is independent of glucose concentration in arterial blood above a certain concentration. Should this be the mechanism, then it might be expected that intraruminal infusions of butyric acid would also increase milk yield in contrast to the findings of Rook (see Table $\mathrm{I}$ ), since it is known that BOH is used as a substrate for oxidative metabolism by many tissues in the ruminant (see Armstrong, I965). If butyrate does not increase milk yield the explanation may be in the use of $\mathrm{BOH}$ solely for milk fat synthesis (see Linzell, Annison, Fazakerley \& Leng, 1967).

Clearly much remains to be understood before it is possible to account for the 
known nutritional effects on milk secretion. Techniques are now available for measuring VFA production in the rumen, and by the use of intestinal re-entrant cannulas, the end-products of digestion arising posterior to the abomasum. They are also available for measuring the entry rates of specific metabolites into the body processes and their contribution to oxidative metabolism. The results of such studies with lactating dairy cows if linked to energy balance studies such as those obtained by Flatt (1966) and his co-workers, should make progress in this field very rapid.

\section{REFERENCES}

Annison, E. F. (1960). Aust. F. agric. Res. II, 58.

Annison, E. F., Leng, R. A., Lindsay, D. B. \& White, R. R. (1963). Biochem. F. 88, 248.

Armstrong, D. G. (1965). In Physiology of Digestion in the Ruminant, p.272. [R. W. Dougherty, editor.] Washington: Butterworths.

Armstrong, D. G., Seeley, R. S. \& MacRae, J. C. (1967). Proceedings of the Fourth Symposium on Energy Metabolism in Farm Livestock, Jablonna, Poland. (In the Press.)

Balch, C. C., Broster, W. H., Rook, J. A. F. \& Tuck, V. J. (1965). F. Dairy Res. 32, I.

Bath, I. H. \& Rook, J. A. F. (1963). F. agric. Sci., Camb. 6r, 341.

Bath, I. H. \& Rook, J. A. F. (1965). 7. agric. Sci., Camb. 64, 67.

Bergman, E. N., Roe, W. E. \& Kon, K. (Ig66). Am. F. Physiol. 21 ז, 793.

Bigwood, E. J. (1964). In The Role of the Gastrointestinal Tract in Protein Metabolism, p.155. [H. N. Munroe, editor.] Oxford: Blackwell Scientific Publications.

Castle, M. E., Drysdale, A. D. \& Waite, R. (rg6r). Y. Dairy Res. 28, 67.

Clarke, E. M. W., Ellinger, G. M. \& Phillipson, A. T. (1966). Proc. R. Soc. B 166, 63.

Donefer, E., Lloyd, L. E. \& Crampton, E. W. (1962). F. Anim. Sci. 21, 993.

Flatt, W. P. (1966). 7. Dairy Sci. 49, 230.

Holmes, W., Arnold, G. W. \& Provan, A. L. (1960). F. Dairy Res, 27, 19г.

Huber, J. T. \& Boman, R. L. (1966a). F. Dairy Sci. 49, 395.

Huber, J. T. \& Boman, R. L. (1966b). \%. Dairy Sci. 49, 8 I6.

Karr, M. R., Little, C. O. \& Mitchell, G. E. (I966). F. Anim. Sci. 25, 625.

Kirchgessner, M., Friesecke, H. \& Koch, G. ( 1967$)$. Nutrition and the Composition of Milk. London: Crosby Lockwood.

Leng, R. A. \& Brett, D. J. (Ig66). Br. F. Nutr, zo, 54I.

Leng, R. A. \& Leonard, G. J. (1965). Br. 7. Nutr. 19, 469.

Linzell, J. L., Annison, E. F., Fazakerley, S. \& Leng, R. A. (1967). Biochem. F. 104, 34.

McClymont, G. L. \& Vallance, S. (1962). Proc. Nutr. Soc. 2I, xli.

Moe, P. W., Reid, J. '1. \& Tyrrell, H. F. (1965). F. Dairy Sci. 48, то53.

Moore, J. H. \& Steele, W. (I968). Proc. Nutr. Soc. $27,66$.

Opstvedt, J., Baldwin, R. L. \& Ronning, M. (1967). F. Dairy Sci. 5o, ro8.

Opstvedt, J. \& Ronning, M. (1967). 7. Dairy Sci. 5o, 345.

Rook, J. A. F. (I96ra). Dairy Sci. Abstr. 23, 25 I.

Rook, J. A. F. (1961b). Dairy Sci, Abstr. 23, 303 .

Rook, J. A. F. (1964). Proc. Nutr. Soc. 23, 7 I.

Rook, J. A. F. \& Balch, C. C. (1961). Br. F. Nutr. 15, 36 r.

Rook, J. A. F., Balch, C. C. \& Johnson, V. W. (1965). Br. F. Nutr. I9, 93.

Rook, J. A. F. \& Line, C. (1961). Br. F. Nutr. 15, 109.

Rook, J. A. F. \& Line, C. (1962). Int. Dairy Congr. xIv. Copenhagen A, p.57.

Rook, J. A. F., Line, C. \& Rowland, S. J. (1960). \%. Dairy Res. $27,427$.

Storry, J. E. \& Rook, J. A. F. (1965a). Biochem. 9. 96, 210.

Storry, J. E. \& Rook, J. A. F. (1965b). Br. F. Nutr. 19, ror.

Storry, J. E. \& Rook, J. A. F. (1966). Br. F. Nutr. 20, 217.

Van Soest, P. J. (1963). 7. Dairy Sci. 46, 204.

Williams, V. J. \& Christian, K. R. (1956-7), N.Z. Fl Sci. Technol. 36A, 403. 